An examination of involvement in relation to superannuation consumption.

\author{
Dr Debra Grace \\ Senior Lecturer \\ Griffith University, Gold Coast, Australia \\ Dr Scott Weaven \\ Lecturer \\ Griffith University, Gold Coast, Australia \\ Ms Sharlene Anderson, \\ Lecturer \\ Bond University, Gold Coast, Australia
}

SUBMITTED TO: Journal of Financial Services Marketing

Contact Details:

Dr Debra Grace

Department of Marketing

Griffith Business School

Griffith University

PMB 50

Gold Coast Mail Centre

Queensland 9726

Australia

Phone: 617-55528027

Fax: 617-55528085

Email: D.grace@griffith.edu.au 


\section{An examination of involvement in relation to superannuation consumption.}

This study examines consumer involvement in the context of superannuation in order to gain an understanding of this important consumer behaviour construct in a forced consumption situation i.e. compulsory superannuation. In doing so, associations between involvement and consumer knowledge, consideration of future consequences (CFC), age and education are proposed and tested. Data were gathered via self-report survey from 329 respondents from four regions in south-east Queensland representing a diverse socioeconomic spread. The results of regression analysis clearly indicate that subjective knowledge, age and CFC are positively associated with involvement in relation to superannuation. Findings in relation to objective knowledge and education were not significant. The findings indicate, that in practical terms, marketing efforts should be concentrated, not only on the provision of information in relation to superannuation, but, more importantly, on attitude change with the objective of stimulating need recognition in younger superannuation consumers. 


\section{INTRODUCTION}

The superannuation landscape in Australia provides for a unique consumption situation. Superannuation contributions (via the Superannuation Guarantee Charge) are mandatory for most employed consumers resulting in 'forced' rather than 'voluntary' consumption behavior. Thus, demand appears to be stimulated by government regulation which has a significant impact upon the consumer decision-making process. In essence, Government intervention has denied the consumer the experience (and consequential learning related to need recognition) within the initial stages of the decision-making process. ${ }^{1}$ As a result, subsequent consumption behaviour should also be affected. For example, the motivation for consumers to engage in search and evaluation activities (i.e. information gathering and processing) may have been diminished as need recognition (in relation to superannuation) occurs at the societal level (i.e. recognized by the government), rather than at the individual level (i.e. recognized by the consumer). Given that recent legislative change now allows the individual super fund choice (previously nominated by employers), it is likely that many important financial decisions may be determined on the basis of very little knowledge of superannuation, in general, and, more specifically, fund performance. This may result from both knowledge deficiency and a lack of consumer interest or perceived relevance (particularly with younger consumers) in relation to superannuation. This study examines this issue of relevance (i.e. consumer involvement) in the context of superannuation in order to gain an understanding of this important consumer behaviour construct in a forced consumption situation i.e. compulsory superannuation. In doing so, we propose and test associations between involvement and 
consumer knowledge, consideration of future consequences (CFC), age and education. As a result, we gain valuable insight into the initial stages of the consumer decisionmaking process, in the context of superannuation, and establish a benchmark for future research in this area.

\section{THEORETICAL DEVELOPMENT}

Need recognition occurs when there becomes an apparent difference between actual and desired states which is sufficient to motivate action in order to rectify the disparity. ${ }^{2}$ In the case of superannuation, need recognition is complex because, at the individual level, the need develops over time. Often, it is not until the individual gets closer to retirement age that the realization of the discrepancy between their actual and desired states becomes apparent. At this point it is often too late to rectify any such incongruities. However, under new superannuation legislation, consumers will have the option of choosing a preferred super fund which will expose them to the information search and evaluation stages of consumer decision-making, regardless of whether need recognition has occurred or not. At this point, those people who believe that superannuation is personally relevant to them (recognized the need), may engage in extensive information search and be inclined to effectively exercise their right to super fund choice. Further, additional knowledge of investment alternatives, within the context of involvement theory, may encourage concomitant increases in the level of subsequent information search and processing. On the other hand, it appears plausible that those people who do not perceive superannuation as particularly relevant to them may be less inclined to seek 
out information in order to inform their decisions which may have a resultant deleterious impact upon their accumulated knowledge, subsequent involvement and future financial security.

\section{Consumer Involvement \& Knowledge}

Central to the issue of information processing in the initial stages of consumer decisionmaking is that of involvement, which has been described as being an individual difference variable that has direct consequences on consumption-related behaviours. ${ }^{3}$ Involvement theory suggests that the degree to which consumers will engage in information-processing activity is dependent upon the relevance of the purchase. ${ }^{4}$ For example, when involvement is high there is a higher level of information search and processing. ${ }^{5}$ This often generates negative evaluations of product information (i.e. negative attitudes) and the likelihood of rejection is greater as the consumer is more discerning. ${ }^{6,7}$ Conversely, when involvement is low there is limited information search and, as a result, consumers are more susceptible to persuasion (generally through peripheral advertising cues) than highly involved consumers. ${ }^{\text {4, } 8}$

The nature of involvement dictates its close relationship with the amount of knowledge consumers have in relation to a particular product category (i.e., high involvement equates with higher knowledge). For example, those who are involved will engage in more information search activities and, as a result, gain more knowledge. Research suggests that consumer knowledge is comprised of two main components, that being 
subjective and objective product knowledge. Subjective knowledge refers to what the consumer thinks they know, whereas objective knowledge relates to what the consumers actually know, measured via a test. ${ }^{9}$ Previous research suggests that subjective and objective knowledge influence information processing in different ways. In particular, objective knowledge is more likely to influence the amount of information sought, whereas subjective knowledge is closely related to purchase-related behaviours and decision-making. ${ }^{9}$ However, regardless of the influence of knowledge upon behaviour, it would be expected that an individual who is more involved with superannuation would be more likely to have greater knowledge (both subjective and objective) regarding superannuation. On this basis, the following hypotheses are proposed:

H1: Subjective knowledge will have a significant positive association with consumer involvement in relation to superannuation.

H2: Objective knowledge will have a significant positive association with consumer involvement in relation to superannuation.

\section{Age}

Although past research suggests that experience is another category of consumer knowledge, ${ }^{10}$ more contemporary thought suggests that experience is a determinant of information search behaviours and (both) subjective and objective knowledge. ${ }^{9}$ Early research by Taylor $^{11}$ revealed a high correlation between age and experience when 
examining managerial-level information processing and decision-making. Later research utilized age as a measure of experience in assessing the cognitive search strategies of financial analysts. ${ }^{12}$ Other research has found that older consumers (who possess higher levels of financial experience and knowledge) engage in higher information search behaviors than younger consumers, when evaluating investment alternatives. ${ }^{13}$ Similarly, Lin and Lee ${ }^{14}$ advocate that older consumers have more accumulated experience in making investment decisions which equates to higher levels of accumulated knowledge. On this basis, and considering that as consumers age they are more likely to realize the importance of their superannuation plan in facilitating their retirement lifestyle preferences (i.e. more involved), it is hypothesised that:

H3: Age will have a significant positive association with consumer involvement in relation to superannuation.

\section{Education}

It has also been argued that better-educated consumers have a more extensive knowledge structure, tend to gather more information and are capable of assimilating complex information. ${ }^{15,16}$ Previous research has found a positive linear relationship between an individual's education level and information search involving purchases of durable goods. ${ }^{17,18}$ In their study of pre-purchase online search behaviours of automobile shoppers, Klein and Ford ${ }^{19}$ found a significant positive relationship between education and the number of information sources used. Within the financial services context, Lin 
and Lee ${ }^{14}$ determined that individuals with a college degree were more likely to search for information regarding different financial investment alternatives. Given that individuals who are highly involved also engage in greater information search, it may be that those individuals who are highly involved with superannuation tend to have higher levels of education. This appears plausible given that superannuation is a complex product requiring the assimilation of complex information. On this basis, it is hypothesised that:

H4: Education will have a significant positive association with consumer involvement in relation to superannuation.

\section{Consideration of Future Consequences}

Furthermore, given that superannuation is characterized by the future-orientation of the product's benefits, it would be expected that those consumers who are highly involved in superannuation would have an appreciation of the way in which their immediate behaviour will influence future consequences. Defined as "a stable individual difference that reflects the extent to which distant versus immediate consequences of behaviour are

considered” ${ }^{20}$ (p. 117), consideration of future consequences (CFC) has been shown to predict health behaviours associated with alcohol use, cigarette use and environmental issues. $^{20}$ 
CFC theory suggests that for some individuals, engaging in certain behaviors may be guided by a perceived trade-off between those personal costs and benefits associated with a given behavior in the short term, and those costs and benefits (associated with different behaviors) in the long term. ${ }^{21}$ Therefore, the manner in which an individual views time (which is considered as a valid and reliable individual difference) ${ }^{22}$ is predictive of resultant behavioral choices. ${ }^{23}$ Although CFC is considered to be relatively stable over time $^{24}$, there is some evidence that individual experiences may influence a person's temporal orientation. ${ }^{25}$ Moreover, an individual's personality traits, age and reference groups may impact upon an individual's decisional and behavioral choices. ${ }^{26,27}$ Given the above discussion, it would be expected that CFC may also play an important role in predicting involvement in relation to superannuation. As such, it is hypothesised that:

H5: Consideration of future consequences (CFC) will have a significant positive association with consumer involvement in relation to superannuation.

\section{RESEARCH DESIGN}

The research design included the development of a self-report survey, which included measures to capture the constructs of interest in this study. The survey included scale items to measure involvement, ${ }^{28}$ consideration of future consequences ${ }^{25}$ and subjective knowledge. ${ }^{9}$ The 4 -item involvement scale was adapted from Beatty and Talpade ${ }^{28}$ who used the scale to measure product category involvement and reported strong reliabilities 
of the scale at .74 and .80. Consideration of future consequences (CFC) was taken from Petrocelli ${ }^{25}$ who developed an 8-item CFC scale demonstrating strong reliability (.82) and dimensionality. Subjective knowledge was measured by a short 5-item reliable scale developed by Flynn and Goldsmith ${ }^{9}$ and tested over 8 separate data collections which produced reliability estimates ranging from .87 to .93 . In relation to objective knowledge, four items relating to superannuation in general were developed specifically for this study. Demographic information regarding age and education was also collected. Changes to wording of the items were adapted to reflect the context of this study and these are shown in Table 1 along with corresponding factor loadings. A 7-point Likert scale ranging from "strongly disagree" (1) to "strongly agree" (7) was used throughout the survey for all measurements except for objective knowledge. Items measuring objective knowledge had response options of “yes”, “no” and “don’t know”.

\section{--- Insert Table 1 here ---}

A stratified sampling method was used whereby four small regions in south-east Queensland were specifically selected for data collection in order to achieve a diverse socio-economic spread in relation to the sample. Within each region, streets were randomly selected and surveys (with reply paid mail envelopes) were letter-box dropped in these areas. Two surveys per household were distributed in order to capture the responses of not only the main household earner but also others within the family. Of the 2000 surveys distributed, 329 surveys were returned, representing a response rate of $16 \%$. The response rate obtained, while reasonably low, is indicative of mail survey response rates. The resulting sample represented demographic diversity and was comprised of 51\% 
female and 49\% male; mean age was 34 years (ranged between 18 and 62 years); 49\% casual/part-time employed and 51\% full-time employed and income levels of 49\% earning under $\$ 30000$ per annum, 31\% earning between $\$ 30000$ and $\quad \$ 60000$ per annum and the remaining 20\% earning over $\$ 60000$ per annum. This sample is quite representative of the region where data were collected. For example, the large proportion of the sample being casually employed is a product of tourism being the major industry within the region.

\section{RESULTS}

\section{Preliminary Analysis of Scales}

Firstly, each variable was visually inspected for normality, skew and kurtosis and the presence of outliers. Histograms were deemed appropriate at this stage to provide the best "overall” picture of each variable across a small range of scores (1 to 7). In addition to visual inspection, each variable was analysed via test of skewness and kurtosis. Overall the data did not appear to be problematic, with all statistics falling within acceptable ranges. For example, skew and kurtosis values were less than \pm 2.00 , indicating that the frequency distributions were considered normal. Similarly, the data was inspected for the presence of outliers and none were detected. For example, scores did not fall outside the range of 3 to 4 standard deviations, which is the recommended criteria for detecting outliers for large samples.

Prior to the main analysis of the study, the scales used to measure the relevant constructs underwent preliminary analysis in order to examine the reliability and factor structures of 
the scales prior to computing composite measures for each variable. Factor analysis revealed that all scales were unidimensional with eigenvalues greater than 1 , factor loadings ranged between .74 and .93 and these were above the recommended level of .50. ${ }^{29}$ Furthermore, Cronbach’s Alpha estimates ranged from .81 to .86 which were above .70 ${ }^{30}$ thus indicating internal consistency of the scales (refer Table 2 for summary of these results). This being the case, the data were deemed appropriate for the computation of mean values to form composite measures for each of the variables. The means of the resulting composite variables ranged from 3.22 to 4.79 and the standard deviations ranged from 1.13 to 1.57 (refer Table 2). In relation to objective knowledge, a correct answer was given a score of 1 and wrong answers or “don’t know” answers a score of zero. These were then summed to produce an overall score in relation to objective knowledge. So the responses were scaled according to the level of knowledge held by respondents, a constant of 1 was added to each respondent's score, thus eliminating any zero scores. The result was that objective knowledge was recorded for each respondent on a scale ranging from 1 (no knowledge) to 5 (very knowledgeable). (A similar scaling technique was used by Dutcher, Finley, Luloff and Johnson ${ }^{31}$ when scaling responses to 3 Venn diagrams used to measure environmental connectivity).

Prior to conducting regression analysis, bivariate correlations between the constructs were examined in order to establish the relationships between variables (as shown in Table 3). While the majority of correlations were significant, they were not high enough to indicate that multicollinearity would be problematic in the ensuing analysis. 


\section{Main Analysis}

In order to address the hypotheses, regression analysis was conducted to examine the effect of the independent variables (subjective knowledge, objective knowledge, age, education and CFC) on the dependent variable (involvement). The results presented in Table 4 indicate that $25 \%$ of the variance in involvement is accounted for by the independent variables (F statistic of 20.16, $\mathrm{p}<.001$ ). The results indicate that subjective knowledge had a significant positive effect on involvement with a beta weight of .27 ( $\mathrm{p}<$ $.05)$, as did age with a beta weight of $.27(\mathrm{p}<.05)$ and CFC with a beta weight of .15 ( $\mathrm{p}<$ .05). However, objective knowledge and education were not significant. On this basis H1, H3 and H5 were supported, whereas H2 and H4 were not.

\section{LIMITATIONS}

Limitations of this study include issues relating to non-response bias, generalisability and measurement. Firstly, non-response bias was not tested, however, the variability of responses and demographic spread of the sample suggests that any such bias may have been minimal. Secondly, generalisations of the findings beyond the South- East region of Queensland should be treated with caution. However, given that superannuation is dictated by Federal legislation, the issues faced by consumers of superannuation are the same across the country. Therefore, it is suggested that such generalisations could be reliable. Also, as commonalities exist between Australia and other countries (e.g. Sweden, Chile and Mexico) in relation to the mandatory nature of superannuation 
(pension plans) and issues surrounding ageing populations, the findings may be of interest to other nations. In addition, the findings in relation to involvement are limited by the measures used which reflect relevance and interest in superannuation rather than active involvement. As such, future research should address deficiency. Lastly, other variables such as income, job status and gender were not considered in assessing an individuals' level of education, search time costs and subsequent involvement. Future research should investigate the role (and interaction effects) of these variables in the context of superannuation services evaluation.

\section{DISCUSSION}

The results clearly indicate that subjective knowledge, age and CFC are positively associated with involvement in relation to superannuation. Therefore, older individuals who think they know a lot about superannuation and consider the future, rather than the immediate, consequences of their actions are more likely to be involved or perceive greater relevance in relation to superannuation. While these results make sense, what is surprising is the non-significant findings in relation to both objective knowledge and education. On this basis, it appears that a difference exists between individuals, who have an interest in superannuation, think they know about superannuation as opposed to what they actually know. This is possible given the complex nature of superannuation. Therefore, individuals may feel knowledgeable about superannuation and this may go hand in hand with their high level of interest. However, if (unbeknownst to them) the knowledge that they possess is inaccurate or incomplete, then inappropriate financial 
decisions may result. Moreover, as decision-making is more closely linked to subjective knowledge as opposed objective knowledge, ${ }^{9}$ such decisions are likely to occur. It may also be expected that, as the individual's decision would be based on what they perceive to be sound knowledge, the decision may come with a certain level of confidence. Given this, the highly involved consumer may actually engage in less information search prior to the decision as opposed to those who are less involved and more wary in relation to superannuation decision-making.

The non-significant association of education with involvement may be the result of the significant influence of age in relation to superannuation involvement. For example, although older consumer may be more likely to have an interest in superannuation, it does not necessarily mean that older consumer possess a higher level of education. In fact, it is more likely that younger consumers would show higher levels of formal education than older consumers. Furthermore, this finding is consistent with historical evidence from the UK whereby changes to retirement fund policy resulted in decisions that incurred losses that were not confined to less-educated consumers, but included many consumers with higher levels of education (eg. trained professionals, teachers and academics) who had made poor pension plan choices. ${ }^{32}$

The findings in relation to age and superannuation involvement may well be indicative of an absence of recognition of need in younger people. Given the potential for economic detriment to individuals in the long run, not to mention the burden that non self-funded retirees will place on society, this is an issue that needs addressing. In particular, 
marketing efforts should be concentrated, not only on the provision of information in relation to superannuation, but, also on attitude change with the objective of stimulating need recognition in younger (low involvement) superannuation consumers. Just as advertising campaigns, combined with Government policy, have instigated change in relation to consumer attitudes and behaviour regarding social issues, such as smoking, recycling, drink driving etc., similar strategies should be utilised in the context of superannuation. In learning by our marketing successes regarding attitudinal and behavioural change in the past, ${ }^{6}$ we can enhance the effectiveness of our marketing efforts in relation to superannuation in the future.

\section{Conclusion}

Issues related to self-funded retirement (eg. superannuation, pension plans) are of paramount importance in societies characterized by ageing populations. While the importance of appropriate education and information dissemination regarding "super choice” has been highlighted by the Wallis Committee (commissioned to investigate superannuation choice in Australia in 1996), issues surrounding attitudinal change in high and low involvement consumer segments has been largely overlooked. No amount of education or information dissemination will be sufficient if consumers are not internally motivated to seek out and evaluate this information for application in their present and future decision-making endeavours. 


\section{REFERENCES}

1. Dewey, J. (1910) 'How we think’, D.C. Heath and Company, Boston.

2. Hill, C.J. (2001) 'The nature of problem recognition and search in the extended health care decision’, Journal of Services Marketing, Vol. 15, No. 6, pp. 454-479.

3. Gabbott, M. and Hogg, G. (1999) 'Consumer involvement in services: A replication and extension', Journal of Business Research, Vol. 46, pp. 159-166.

4. Bruner, G.C. and Pomazal, R.J. (1988) 'Problem recognition: The crucial first stage of the consumer decision process', Journal of Consumer Marketing, Vol. 5, No. 1, pp. 53.63.

5. Brucks, M. (1985) 'The effects of product class knowledge on information search behavior’, Journal of Consumer Research, Vol. 12, No. 1, pp. 1-15.

6. Malhotra, N. K. (2005) 'Attitude and effect: New frontiers of research in the $21^{\text {st }}$ century’, Journal of Business Research, Vol. 58, pp. 477-482.

7. Schiffman, L., Bednall, D. O’Cass, A., Paladino, A and Kanuk, L. (2005)

'Consumer Behaviour', $3{ }^{\text {rd }}$ Edition, Pearson Education Australia, Frenchs Forest, NSW.

8. Sengupta J., Goodstein R and Boninger D. (1997) 'All cues are not created equal: obtaining attitude persistence under low-involvement conditions', Journal of Consumer Research, Vol. 23 (March), pp. 351-61.

$9 \quad$ Flynn, L. and Goldsmith, R. (1999) 'A short reliable measure of subjective knowledge', Journal of Business Research, Vol. 46, No. 1, pp. 57-66.

10. Bettman, J. R. and Whan Park, C. (1980) 'Effects of prior knowledge and experience and phase of the choice process on consumer decision processes: A Protocol analysis', Journal of Consumer Research, Vol. 7 (December), pp. 234248.

11. Taylor, R. N. (1975) 'Age and experience as determinants of managerial information processing and decision-making performance', The Academy of Management Journal, (March), pp. 74-81.

12. Hunton, J. E. and McEwen, R. A. (1997) 'An assessment of the relation between analysts' earnings forecast accuracy, motivational incentives and cognitive information search strategy', The Accounting Review, Vol. 72, No. 4, pp. 497515. 
13 Agnew, J. R. and Szykman, L. R. (2005) 'Asset allocation and information overload: The influence of information display, asset choice and investor experience', The Journal of Behavioural Finance, Vol 6, No. 2, pp. 57-70.

14. Lin, Q. and Lee J. (2004) 'Consumer information search when making investment decisions’, Financial Services Review, Vol 13, pp. 319-332.

15 Kassarjian, H. H. (1981) 'Low Involvement - A second look', in Advances in Consumer Research, K. B. Monroe (ed), Ann Arbor, MI, Association for Consumer Research, pp. 31-34.

16. Schmidt, J.B. and Spreng, R.A. (1996) 'A proposed model of external consumer information search,' Journal of the Academy of Marketing Science, Vol. 24, pp. 246-256.

17. Kiel, G. C. and Layton, R. A. (1981) 'Dimensions of consumer information seeking behaviour’, Journal of Marketing Research, Vol. 28, pp. 233-239.

18. Ratchford, B. T., Lee, M. S and Talukdar, D. (2003) 'The impact of the Internet on the search for automobiles', Journal of Market Research, Vol. XL (May), pp. 193-209.

19. Klein, L. R. and Ford, G. T. (2003) 'Consumer search for information in the digital age: An empirical study of prepurchase search for automobiles', Journal of Interactive Marketing, Vol. 17, No. 3, pp. 29-49.

20. Sirois, F.M. (2003) 'Procrastination and intentions to perform health behaviors: The role of self-efficacy and the consideration of future consequences', Personality and Individual Differences, Vol. 37, pp. 115-128.

21. Cooper, H., Wood, P.K., Orcutt, H.K. and Albino, A. (2003) 'Personlaity and the predisposition to engage in risky or problem behaviors during adolescence', Journal of Personality and Social Psychology, Vol. 84, No. 2, pp. 390-410.

22. Zimbardo, P.G. and Boyd, J.N. (1999) 'Putting time in perspective: A valid, reliable and individual-differences metric', Journal of Personality and Social Psychology, Vol. 77, No. 6, pp. 1271-1288.

23. Lewin, K. (1951) 'Field theory in social sciences: Selected theoretical papers', Harper, New York.

24. Strathman, A., Gleicher, F., Boninger, D. S. and Edwards, C.S. (1994) ,The consideration of future consequences: Weighing immediate and distant outcomes of behavior', Journal of Personality and Social Psychology, Vol. 66, No. 4, pp. 742-752. 
25. Peterocelli, J. V. (2003) 'Factor validation of the consideration of future consequences scale: Evidence of a shorter version', The Journal of Social Psychology, Vol. 143, No. 2, pp. 405-413.

26. Andreasen, A. R. (1995) 'Marketing social change: Changing behaviour to promote health, social development, and the environment, Jossey-Bass Publishers, San Francisco.

27. Bagozzi, R. P. (1979) 'Towards a formal theory of marketing exchanges, in S. W. Brown and R. P. Fisk (eds.) Marketing Theory: Distinguished Contributions, John Wiley \& Sons, New York, pp. 136-145.

28 Beatty, S. and Talpade, S. (1994) 'Adolescent influence in family decisionmaking: A replication with extension', Journal of Consumer Research, Vol. 21 (September), pp. 332-341.

29. Shi, X. and Wright, P. C. (2001) 'Developing and validating an international business negotiator's profile', Journal of Managerial Psychology, Vol. 16, No. 5, pp. 364-389.

30. Hair, J.F., Jr. Anderson, R.E., Tatham, R.L. and Black, W.C. (1998) 'Multivariate Data Analysis’, 5th Edition, Prentice Hall, Upper Saddle River, NJ.

31. Dutcher, D.D., Finley, J.C., Luloff, A.E. and Johnson, J.B. (2007) 'Connectivity with nature as a measure of environmental values', Environment and Behaviour.

32. Kennedy, R. (1998) 'Focus will be on understanding choice’, Superfunds (April), p. 13. 
Table 1. Survey Items and Factor Loadings

\begin{tabular}{|c|c|}
\hline Survey Item & $\begin{array}{c}\text { Factor } \\
\text { Loading }\end{array}$ \\
\hline $\begin{array}{l}\text { Involvement } \\
\text { In general, I have a strong interest in superannuation. } \\
\text { Superannuation is very important to me. } \\
\text { Superannuation matters to me. } \\
\text { I get bored when other people talk to me about superannuation.** }\end{array}$ & $\begin{array}{l}.82 \\
.93 \\
.89 \\
.74\end{array}$ \\
\hline $\begin{array}{l}\text { Subjective Knowledge } \\
\text { Among my circle of friends, I am one of the experts on superannuation. } \\
\text { I know pretty much everything about superannuation. } \\
\text { I do not feel very knowledgeable about superannuation. }{ }^{* *} \\
\text { Compared to most other people, I know less about superannuation. }{ }^{* *} \\
\text { When it comes to superannuation, I really don’t know a lot.** }\end{array}$ & $\begin{array}{l}.86 \\
.79 \\
.79 \\
.76 \\
.84\end{array}$ \\
\hline $\begin{array}{l}\text { Consideration of Future Consequences } \\
\text { I only act to satisfy immediate concerns, figuring the future will take care of itself.** } \\
\text { I generally ignore warnings about possible future problems because I think the problems will be } \\
\text { resolved before they reach crisis level.** } \\
\text { In general, the future consequences of my behaviour are more important to me than the immediate } \\
\text { consequences. } \\
\text { When I think about doing something, I generally think about how it will affect me in the future, } \\
\text { rather than now. } \\
\text { Generally, my decision to do things is influenced by the thought of future consequences rather than } \\
\text { immediate consequences. }\end{array}$ & $\begin{array}{l}.79 \\
.76 \\
.75 \\
.82 \\
.83\end{array}$ \\
\hline $\begin{array}{l}\text { Objective Knowledge } \\
\text { Superannuation is safe because it is guaranteed. } \\
\text { If I make voluntary contributions into my super fund, I can withdraw that money if I need it. } \\
\text { Superannuation trustees must distribute member funds according to their will in the case of death. } \\
\text { Providing you can prove you have retired, you can access all of your superannuation regardless of } \\
\text { age. } \\
\text { (The correct answer for each of these statements is "no") }\end{array}$ & $\begin{array}{l}\mathrm{n} / \mathrm{a} \\
\mathrm{n} / \mathrm{a} \\
\mathrm{n} / \mathrm{a} \\
\mathrm{n} / \mathrm{a}\end{array}$ \\
\hline
\end{tabular}


Table 2 Preliminary Analysis of Scales and Composite Variables Descriptive Statistics

\begin{tabular}{lccc} 
Variable & No of Items & Loadings & Cronbach's Alpha \\
\hline Involvement & 4 & $.74-.93$ & .82 \\
Subjective Knowledge & 5 & $.86-.86$ & .86 \\
CFC & 5 & $.75-.83$ & .81 \\
& & & \\
Composite Variables & Mean & Standard Deviation & \\
\hline Involvement & 4.79 & 1.57 & \\
Subjective Knowledge & 3.22 & 1.39 & \\
CFC & 4.62 & 1.13 &
\end{tabular}


Table 3. Bivariate Correlations

\begin{tabular}{|c|c|c|c|c|c|c|}
\hline & Involvement & Subjective K. & Objective K. & CFC & Age & Education \\
\hline Involvement & 1.00 & & & & & \\
\hline Subjective K. & $0.39 * *$ & 1.00 & & & & \\
\hline Objective K. & $0.22 * *$ & $0.26^{\star \star}$ & 1.00 & & & \\
\hline CFC & $0.25^{\star *}$ & $0.21 * *$ & $0.27^{\star *}$ & 1.00 & & \\
\hline Age & $0.37^{\star *}$ & $0.21^{\star *}$ & $0.31 *$ & $0.12^{\star}$ & 1.00 & \\
\hline Education & 0.03 & 0.06 & 0.01 & 0.20 ** & $-0.15^{\star}$ & 1.00 \\
\hline
\end{tabular}


Table 4 Results of Regression Analysis

\begin{tabular}{llccccc}
\hline $\begin{array}{l}\text { Dependent } \\
\text { Variable }\end{array}$ & Independent Variables & Beta & Sig. & $\mathrm{R}^{2}$ & $\begin{array}{l}\text { F- } \\
\text { statistic }\end{array}$ & Sig. \\
\hline Involvement & (H1) Subjective Knowledge & .27 & .001 & .25 & 20.16 & .001 \\
& (H2) Objective Knowledge & .02 & $\mathrm{~ns}$ & & & \\
& (H3) Age & .27 & .001 & & & \\
& (H4) Education & -.04 & $\mathrm{~ns}$ & & & \\
& (H5) CFC & .15 & .004 & & & \\
\hline
\end{tabular}

